\title{
The effect of natural preferences on serving biomechanics: a new approach to the motor skills of tennis players
}

\author{
Kaies Deghaiesa, Caroline Martinª, Pierre Touzarda, Cyril Brechbuhlc, Jean Marc \\ Duboscq $^{c}$, Thibault Lussiana ${ }^{b} \&$ Cyrille Gindre ${ }^{b}$
}

aLaboratory M2S, University Rennes 2, Bruz, France. 'Volodalen Company, Research and Development Department, Chavéria, France. 'French Tennis Federation, National Technical Directorate, Paris, France.

\begin{abstract}
Research has demonstrated the existence of two 'natural preference' profiles in running. The objective of this study was to determine the influence of the natural preferences of terrestrial (with a "posterior and flexion" movement) and aerial (with an "anterior and extension" movement) on the ball speed and impact position during the service of 19 professional players. The results allow to propose a new reading grid of the service technique to consider the preferential motricity of each player while respecting the biomechanical principles.
\end{abstract}

Key words: service, performance, biomechanics, natural preferences.

Received: 10 May 2021

Accepted: 12 June 2021

Corresponding author: Caroline Martin. Email: caroline.martin@ univ-rennes2.fr

\section{INTRODUCTION}

The serve is the only tennis shot that does not depend directly on the opponent. It allows the player to fully express his coordination. Service performance is often measured by ball speed. To hit a hard the serve, players must generate a significant amount of movement that can be captured through the shift in centre of mass (Elliott, 2003). Different motor strategies were highlighted by Elliott et al. (2003) in terms of centre of mass displacement and the amount of movement created in three servers of the same level. Some players will favour a more vertically oriented amount of movement and centre of mass displacement, while others will create a more forward oriented amount of movement related to the displacement of their centre of mass in that direction (Figure 1). The quality of the service also seems to be determined by mechanical principles independent of coordination. This is the case for the height of the ball at contact (Vaverka \& Cernosek, 2013). As height is a non-modifiable factor in players, it is possible to discuss the combined skills of balancing and aiming high at the ball (extension) to improve service performance. To investigate this issue in depth, it is interesting to consider the theory of natural preferences ${ }^{\circledR}$ highlighted in running (Gindre et al., 2016) (Lussiana et al., 2017).

This theory links the efficiency of the runner's stride to their natural motor skills of balance (more anterior or posterior) and coordination (more flexion or extension). Research has shown that there are two "natural preference" profiles in running. The "aerial" profile would optimise stride performance by favouring rebound-extension coordination and anterior balance. Conversely, the coordination of the "terrestrial" profile is oriented towards push-flexion and posterior balance. The explanation could lie in the preferential activation of muscles that are more anterior in "terrestrial" and posterior in "aerial" athletes (Lussiana et al., 2017). These

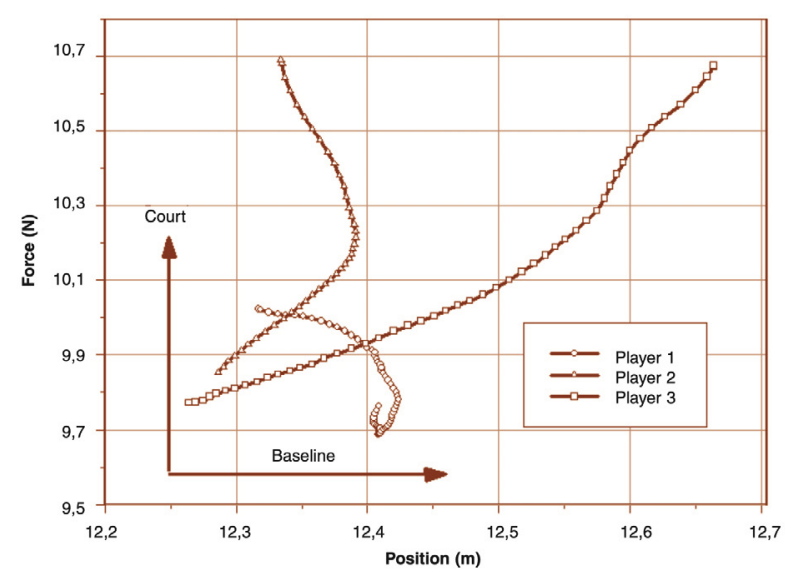

Figure 1: Centre of mass shift on serve for three different players (Elliott, 2003).

preferential muscle groups could jointly ensure balance and the dominant muscle action of athletes. "Terrestrial" athletes would primarily use the anterior muscles to maintain posterior balance (flexion) and to act primarily by pushing forward (concentric pushing). "Aerial" athletes, on the other hand, use their posterior muscle chain to maintain a more anterior balance and a more upward movement (plyometric rebound) (Figure 2).

To date, no studies have focused on exploiting these natural preference models to refine the understanding of tennis players' motor skills. Therefore, the aim of this preliminary exploratory study is to determine the influence of the terrestrial (with a "posterior and flexion" motor pattern) and aerial (with an "anterior and extension" motor pattern) profiles on ball speed and impact position during the serve. 


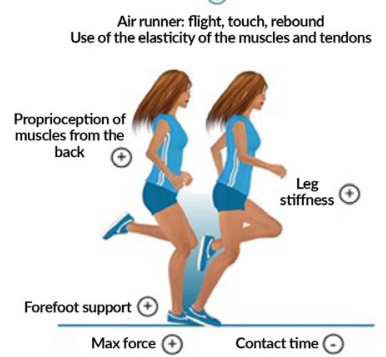

(2)

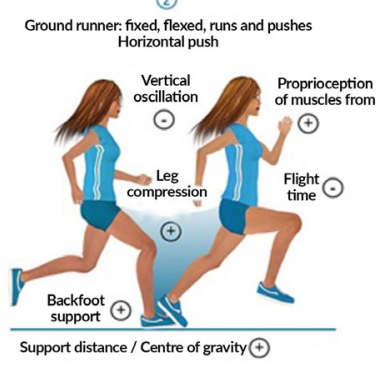

Figure 2. Schematic presentation of the characteristics of the air and ground models in running (Volodalen $\left.{ }^{\circledR}\right)$.

\section{METHODS}

Nineteen professional tennis players participated in this study (age: $20.9 \pm 3.0$ years; height: $1.86 \pm 0.08 \mathrm{~m}$; body mass: 75.7 $\pm 6.8 \mathrm{~kg}$; International Tennis Number 1). The experiments took place on a tennis court surrounded by a motion capture system comprising of 23 optoelectronic cameras (Oqus 7+, Qualisys, Sweden). The players were classified into the "terrestrial" (TER) or "aerial" (AER) group by a Volodalen ${ }^{\circledR}$ expert using the Vscore scale which is based on running observation criteria (Gindre et al., 2016) (Table 1).

Table 1

Characteristics of the aerial (AER) and terrestrial (TER) groups.

\begin{tabular}{|c|c|c|}
\hline & $\operatorname{AER}(n=9)$ & $\operatorname{TER}(n=10)$ \\
\hline Age (years) & $20,8 \pm 2,9$ & $21,0 \pm 3,1$ \\
\hline Height (m) & $1,91 \pm 0,07^{*}$ & $1,80 \pm 0,08$ \\
\hline Weight (kg) & $79,2 \pm 6,9^{*}$ & $72,2 \pm 6,7$ \\
\hline Ranking (ATP) & $\begin{array}{l}507 \pm 591\left(n^{\circ} 17 \text { à }\right. \\
\left.n^{\circ} 1571\right)\end{array}$ & $\begin{array}{l}605 \pm 436 \quad\left(n^{\circ} 81 \text { à }\right. \\
\left.n^{\circ} 1230\right)\end{array}$ \\
\hline Serve technique & Foot-up $(n=9)$ & $\begin{array}{l}\text { Foot-up }(n=7) \text { and foot- } \\
\text { back }(n=3)\end{array}$ \\
\hline
\end{tabular}

$p<0,01^{*}$

Next, the players and their racquets were equipped with reflective body markers to calculate the trajectory of the joint centres and the racquet head (Figure 3 ). The players performed 5 flat serves (first ball) in a target area ( $1 \mathrm{~m} \times 2$ $\mathrm{m}$ at the $\mathrm{T}$ ) in deuce box. The ball speed was measured with a radar (StalkerPro, USA). The impact position in height and depth, the take-off height of the centre of mass at impact and the maximum vertical velocity of the rear hip during the leg thrust were calculated. Given the differences in height and mass between our two groups, a number of variables were standardised. Student's t tests were performed to compare kinematic variables and ball speed between the terrestrial and aerial groups (Statistica 12 software). A Fisher's exact test was used to compare the distribution of serve techniques between the two groups of players (foot-up or foot-back). The significance threshold was set at $p<0.05$.

\section{RESULTS}

Ball speed (relative to subject height and mass) was similar between the 2 groups ( $1.3 \pm 0.1$ versus $1.4 \pm 0.1 \mathrm{~km} / \mathrm{h} / \mathrm{m} / \mathrm{kg}$; $\mathrm{p}=0.059)$. The height of impact relative to the height of the players was identical between AER and TER servers (1.49 \pm $0.02 \times$ height versus $1.49 \pm 0.04 \times$ height; $p=0.903$ ). The AER

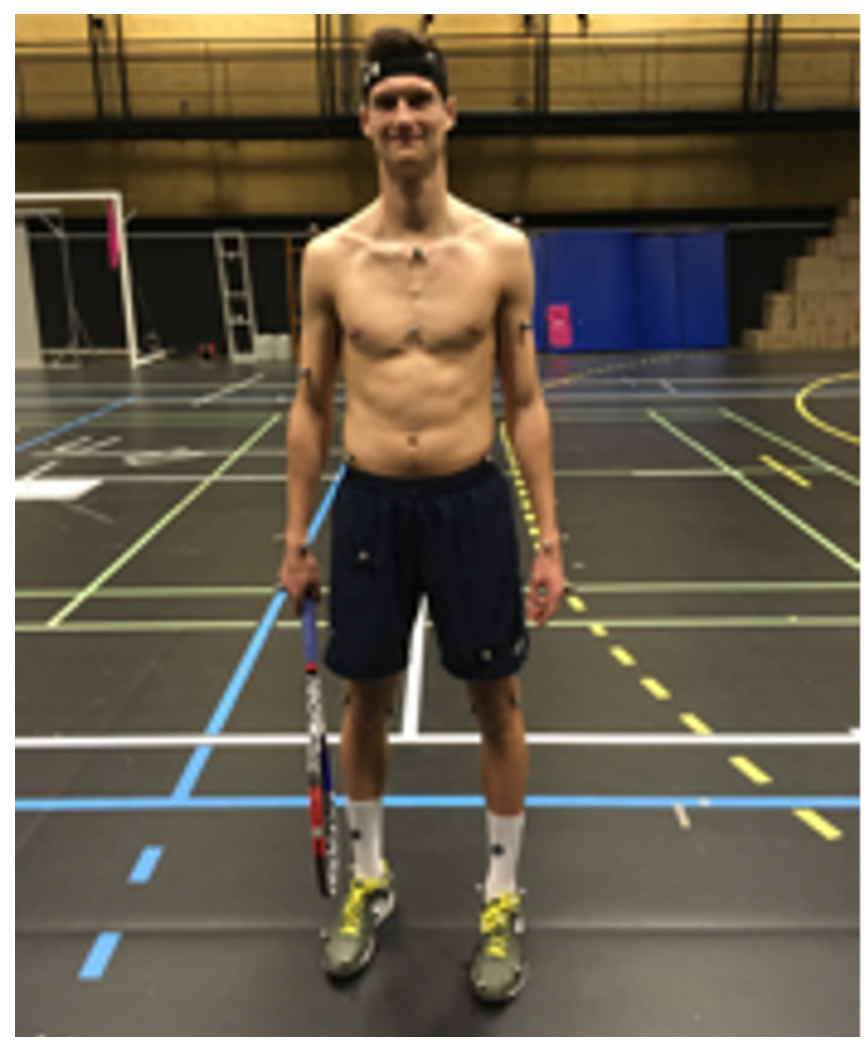

Figure 3. Player and racquet equipped with reflective body markers.

servers lifted their centre of mass at impact more than the TER $(24 \pm 6 \mathrm{~cm}$ vs. $18 \pm 4.0 \mathrm{~cm} ; p=0.02)$. TER servers impacted the ball more forward than AER $(0.37 \pm 0.04 \times$ height versus $0.31 \pm 0.08 \times$ height, $p=0.03$ ). The maximum vertical velocity of the rear hip of the AER servers during the leg thrust was significantly higher $(2.44 \pm 0.24 \mathrm{~m} . \mathrm{s}-1$ versus $2.14 \pm 0.26$ m.s-1; $p=0.01$ ). Fisher's exact test revealed no significant difference in the distribution of support techniques between the two groups $(p=0.211)$.

\section{DISCUSSION}

This research is the first to address the issue of natural preferences ${ }^{\circledR}$ in tennis. In this study, the normalized values of ball speed and impact height tell us that AER and TER players serve equally hard and hit the ball at the same height. However, the TER servers impact the ball further forward than the AER. Conversely, the maximum vertical velocity of the rear hip of the AER servers during the leg drive is significantly higher than that of the TER, causing them to take off more from the terrestrial. As the statistical analysis does not show any difference in the distribution of the serve foot-up or foot-back stance between the two groups, the results obtained for the AER and TER servers seem to be independent of the stance technique used.

Natural preferences may help us to explain the differences obtained between AER and TER servers. Indeed, the AER servers showed a higher take-off height and a higher maximum vertical hip velocity indicating a better ability to propel themselves upwards during the service due to their natural preference based on an extension pattern. Contrary to expectations, the impact height was not significantly higher for the AER servers but is in line with the literature which indicates an optimal impact height around $1.5 \times$ player height. The results concerning the take-off height and the 
vertical speed of the rear hip are in agreement with the work carried out on natural preferences in running. Indeed, Lussiana and Gindre (2016) have shown that AER runners possess coordination based on a preferential upward shift of the centre of mass and muscle functioning in a "rebound" mode (plyometric contraction) (Lussiana \& Gindre, 2016). AER servers have also been shown to produce higher maximal vertical force than TER ones (Gindre et al., 2016) (Lussiana et al., 2017). TER servers have a coordination based on a preferential forward shift of the centre of mass and a "push" mode of operation (concentric contraction) (Lussiana \& Gindre, 2016). The difference in forward impact position on the serve for our two groups tends to confirm the forward "push" mode of operation of TER servers in tennis.

\section{PRACTICAL APPLICATIONS}

In terms of practical applications, this work in connection with the Natural Preference Theory ${ }^{\circledR}$ opens up new perspectives in the field of technical and physical training. Indeed, it is possible to imagine that coaches can provide technical advice adapted to the natural preferences of their players while considering the biomechanical principles of service performance. For example, depending on the "aerial" and "terrestrial" profile, it seems relevant to individualise the advice on the amplitude, duration of the flexion and extension phases of the lower limbs or the orientation of the terrestrial reaction forces during the service, independently of the chosen technique (foot-up or foot-back). Furthermore, since it is known that the progress of each athlete at a given strength training is highly variable and specific (Radnor et al., 2017) (Damas et al., 2019), it appears possible to individualise this advice also during off-court strength training exercises (i.e., much more flexed squats for terrestrial servers).

\section{CONCLUSION AND PERSPECTIVES}

The results of this study for the serve need to be extended to other strokes with reliable data ideally obtained in a competitive ecological context so that the motor skills adopted by the players are as natural as possible. Further work is needed to analyse other parameters related to the "terrestrial" and "aerial" profiles, such as angular velocities, plantar pressures, ball trajectory and lower limb flexion and extension amplitudes. In addition, natural preferences in the way upper body rotations are coordinated have been demonstrated in golf. An associated body is characterised by a rotation in which the shoulder line and the pelvis line work in synergy (e.g., Federer). Conversely, a dissociated body is characterised by an independent rotation between the shoulder and pelvic lines (e.g., Murray) (Figure 4). The
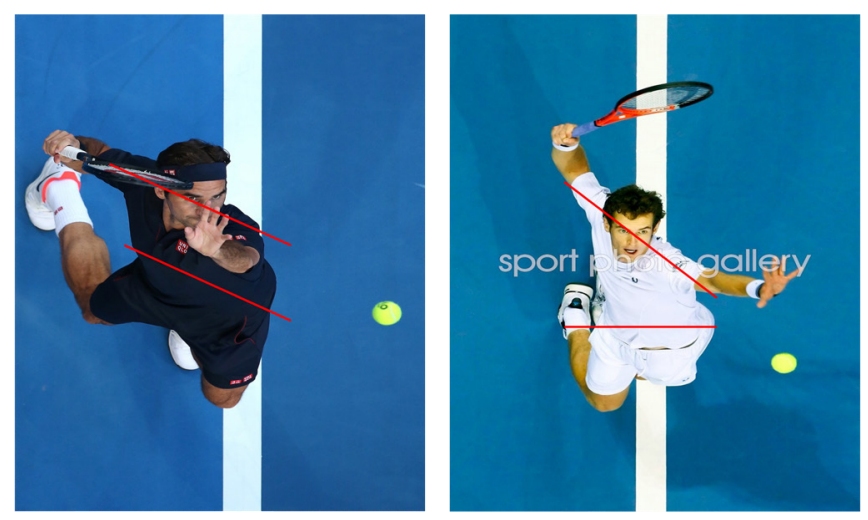

Figure 4: Example of a combined (Federer on the left) and disassociated (Murray on the right) profile.

"associated" and "dissociated" profiles and their influence on the service technique deserve to be investigated in the future. In our opinion, the Natural Preference Theory ${ }^{\circledR}$ is a tool that can help coaches to determine the key points on which to act according to the specificities of each athlete. By no means, this is a question of replacing the dogma of a technical model that would apply in the same way to all by another model, but instead the proposal of a new reading grid that allows the preferential motor skills of each athlete to be considered while respecting the biomechanical principles.

\section{REFERENCES}

Damas, F., Barcelos, C., Nobrega, S., Ugrinowitsch, C., Lixandrao, M., Santos, L., Conceicao, M., 2019, F., \& Libardi, C. (2019). Individual muscle hypertrophy and strength responses to high vs. Low resistance training frequencies. 33(4), 897-901.

Elliott, B. (2003). Biomécanique du tennis de haut niveau (B. Elliott, M. Reid, \& M. Crespo, Eds.). International Tennis Federation.

Gindre, C., Lussiana, T., Hebert-Losier, K., \& Mourot, L. (2016). Aerial and Terrestrial Patterns: A Novel Approach to Analyzing Human Running. International Journal of Sports Medicine, 37(1), 25-29. https://doi.org/10.1055/s-0035-1555931

Lussiana, T., \& Gindre, C. (2016). Feel your stride and find your preferred running speed. Biology Open, 5(1), 45-48.

Lussiana, T., Gindre, C., Mourot, L., \& Hébert-Losier, K. (2017). Do subjective assessments of running patterns reflect objective parameters? European Journal of Sport Science, 17(7), 847-857. https://doi.org/10.1080/17461391.2017.1325072

Radnor, J., Lloyd, R., \& Oliver, J. (2017). Individual Response To Different Forms of Resistance Training in School Aged Boys. The Journal of Strength \& Conditioning Research, 31(3), 787-797.

Vaverka, F., \& Cernosek, M. (2013). Association between body height and serve speed in elite tennis players. Sports Biomechanics / International Society of Biomechanics in Sports, 12(1), 30-37.

Funding statement: The authors received no financial support for the research, authorship, and/or publication of this article.

Conflict of interest statement: The authors declare that they have no conflict of interest.

Copyright (c) 2021 Kaies Deghaies, Caroline Martin, Pierre Touzard, Cyril Brechbuhl, Jean Marc Duboscq, Thibault Lussiana \& Cyrille Gindre

\section{(c) (1)}

This text is under a Creative Commons BY 4.0 license

You are free to Share - copy and redistribute the material in any medium or format - and Adapt the content - remix, transform, and build upon the material for any purpose, even commercially under the following terms:

Attribution: You must give appropriate credit, provide a link to the license, and indicate if changes were made. You may do so in any reasonable manner, but not in any way that suggests the licensor endorses you or your use. 